\title{
Down syndrome in association with features of the androgen insensitivity syndrome
}

\author{
R M Viner, N Shimura, B D Brown, A J Green, I A Hughes
}

\begin{abstract}
Three cases of Down syndrome (DS) are reported in association with features of the androgen insensitivity syndrome (AIS). All were 47,XY, +21 and reared as females. One case had a normal female phenotype, and two cases showed minimal clitoromegaly and labial fusion. Minor genital underdevelopment has been reported as common in males with DS; however, AIS has not previously been associated with DS. Androgen binding studies in genital skin fibroblasts were normal in two cases and in the 46,XY brother of the third who has perineal hypospadias. Mutation screening of the androgen receptor (AR) gene by PCR-SSCP was normal in all cases. Normal androgen binding and the absence of an identified mutation in the coding region of the $A R$ gene is very unusual in AIS, particularly in the complete form. This finding suggests the operation of hitherto unrecognised genes on chromosome 21 with a role in androgen response and sex differentiation.

(f Med Genet 1996;33:574-577)
\end{abstract}

Key words: Down syndrome; androgen insensitivity; sex determination.

The association of Down syndrome (DS) with the androgen insensitivity syndrome (AIS) has not previously been reported. DS is a common genetic disorder arising from trisomy 21 usually secondary to maternal non-disjunction during meiosis, or more rarely from de novo or inherited unbalanced translocations. The androgen insensitivity syndromes are rare $\mathrm{X}$ linked single gene disorders of phenotypic sexual development associated with a male $(46, \mathrm{XY})$ karyotype. ${ }^{1}$ AIS is characterised by a female or ambiguous genital phenotype in a $46, \mathrm{XY}$ male with normal testicular histology and normal testosterone production. Cases show either complete (CAIS) or partial (PAIS) insensitivity to androgen action. The former presents with a normal female phenotype whereas the latter presents in a spectrum from apparently virilised females to undervirilised males.

We report three cases of Down syndrome, two with features of a PAIS phenotype based on minimal clitoral enlargement, and one with a CAIS phenotype. Androgen insensitivity has not previously been reported in Down syndrome. However, studies have reported impaired fertility, ${ }^{2}$ and mildly impaired gonadal function in a high proportion of males with DS.
Increased incidence of anatomical anomalies such as micropenis, ${ }^{3}$ hypospadias, ${ }^{4}$ cryptorchidism, ${ }^{35}$ small testes, and delayed or poor pubertal development have been reported in institutionalised cases of DS. ${ }^{3}$ Two larger studies of male DS cases managed outside institutions differed on the nature of sexual development in DS. Peuschel $e t a l^{6}$ reported normal pubertal gonadal development and secondary sex characteristics, whereas Hsiang et $a l{ }^{7}$ while reporting no increased incidence of genital anomalies with respect to the normal population, nevertheless found penile size and testicular volume to be reduced in comparison to population norms

Male pseudohermaphroditism (incomplete external genital development) in association with DS has been reported in only two previous cases. The first case was a child with a mosaic karyotype $47, \mathrm{XY},+21 / 46, \mathrm{XO},+21$ in whom testes, bifid scotum, perineal hypospadias, and female internal genitalia were shown. ${ }^{8}$ Mosaicism for an XO cell line would explain the ambiguous phenotype in this case. The second case was $47, \mathrm{XY},+21$ with normal testes, fused labioscrotal folds, enlarged phallus, perineal urethral opening, vaginal orifice, and absent internal female genitalia by vaginoscopy. Serum testosterone values were not determined, but 24 hour urinary secretion of androgen metabolites was normal. ${ }^{9}$ The case is suggestive of AIS, but the diagnosis cannnot be substantiated without information on testosterone production and metabolism.

No studies of androgen metabolism or androgen receptor binding have been reported in DS. Major genital anomalies have not been reported by either of two large studies of DS males. ${ }^{67}$ Histology of the testis in DS usually shows markedly decreased spermatogenesis. ${ }^{10}$ Sparse or poor development of androgen dependent hair (pubic, axillary, beard) has been reported in DS. ${ }^{36}$ Testosterone levels have been found to be normal in DS men. ${ }^{36}$ However, the finding of frequently raised $\mathrm{FSH}$ and $\mathrm{LH}$ levels has been interpreted as evidence of mild gonadal dysgenesis in DS. ${ }^{7112}$ In the only study of DS male children, Hsiang et $a l^{7}$ reported that five of 27 had raised LH levels, and eight of 27 showed raised FSH levels.

AIS is a phenotypically heterogeneous syndrome, and the known molecular defects in the androgen receptor (AR) responsible for androgen insensitivity are diverse in nature. ${ }^{1314}$ Studies of androgen binding in genital skin fibroblasts of AIS patients have defined patients as either androgen receptor positive or AR negative. The majority of CAIS patients are receptor negative. In contrast, no clear cut 
Table 1 Clinical features of AIS cases

\begin{tabular}{|c|c|c|c|}
\hline & Case 1 & Case 2 & Case 3 \\
\hline Date of birth & 29.12 .84 & 1.7 .94 & 14.9 .78 \\
\hline Genitalia & & & \\
\hline Phenotype & PAIS & PAIS & CAIS \\
\hline Gonads & Labial testes & Labial testes & Labial testes \\
\hline Clitoromegaly & Mild & Mild & No \\
\hline Urethral opening & Perineal & Perineal & Perineal \\
\hline Scrotum/labia & Unfused & Unfused & Unfused \\
\hline Vaginal orifice & Present & Hypoplastic & Present \\
\hline Uterus & Absent & Absent & Absent \\
\hline Associated conditions & Nil & $\begin{array}{l}\text { Right diaphragmatic } \\
\text { hernia-Morgagni type }\end{array}$ & $\begin{array}{l}\text { Eisenmenger syndrome } \\
\text { and patent ductus } \\
\text { arteriosus; left talipes }\end{array}$ \\
\hline
\end{tabular}

relationship between clinical phenotype and AR binding exists in PAIS patients; the majority of cases show normal receptor binding, although a small subset show qualitative abnormalities in AR binding. ${ }^{15}$ When binding is negative or qualitatively abnormal, mutations are invariably identified in the exons encoding the ligand binding domain of the AR gene, whereas normal AR binding in CAIS is invariably associated with mutations affecting the DNA binding region. A number of cases, particularly PAIS, show normal AR binding and no detectable abnormality in the AR gene. ${ }^{1314}$ This finding suggests that hitherto unrecognised genes may be involved in the regulation of androgen sensitivity in humans.

\section{Case reports}

Cases were drawn from an AIS database established at the Department of Paediatrics, University of Cambridge, partly as a result of a UK wide survey of AIS undertaken through the auspices of the British Paediatric Association Surveillance Unit. Ascertainment of the cases was based upon postnatal chromosomal analysis performed because of clinical features of Down syndrome. Cases 1 and 2 (figure) had slightly abnormal genitalia noted at birth, while case 3 had normal female genitalia (table 1). All cases were non-disjunctional trisomy 21 with karyotypes $47, \mathrm{XY},+21$. A diagnosis of AIS was based upon male karyotype and the results of subsequent investigations. Two cases on balance had features consistent with a PAIS phenotype but only very minimal signs of virilisation, and one case had a typical CAIS phenotype.

\section{Investigations}

These included measurement of androgen production and metabolism after HCG stimulation, basal gonadotrophin concentrations, testicular histology, assessment of AR binding in genital skin fibroblasts, and DNA analysis.

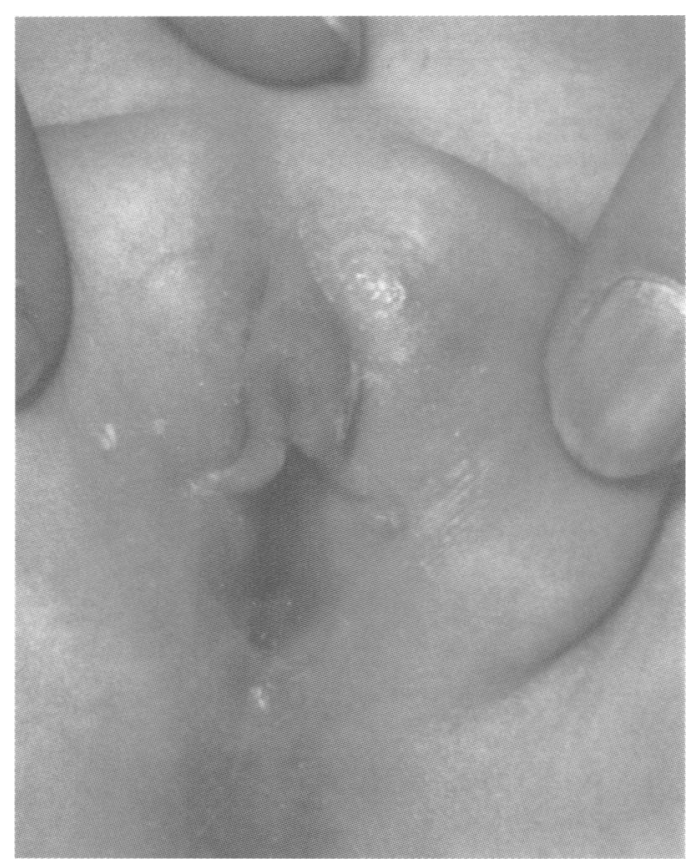

Appearance of the external genitalia in case 2

Normal androgen production and metabolism, and normal testicular histology was found in cases 1 and 2 (table 2). Investigation of case 3 was limited by the associated complex cardiac problems. Interestingly, a 46,XY sib had isolated perineal hypospadias so a genital skin fibroblast line was established at the time of surgical repair to measure AR binding. Androgen binding activity was measured by a whole cell binding assay using genital skin fibroblasts. ${ }^{16}$ Androgen binding was normal in cases 1 and 2, and in the 46,XY sib of case 3 (table 3). All three cases were reared as females. Bilateral gonadectomy was performed on case 1 at 11 years, and bilateral gonadectomy and vulvovaginoplasty on case 2 at 2 months of age. None of the cases has received androgen or oestrogen therapy.

DNA was obtained in case 1 and the sib of case 3 from genital skin fibroblasts and from peripheral blood lymphocytes in cases 2 and 3. Mutation screening of the AR gene was carried out by PCR-single strand conformation polymorphism (SSCP) analysis of DNA as previously published. ${ }^{17}$ All eight exons of the AR gene which encode the ligand binding, DNA binding, and transcriptional activation domains were analysed. There was no evidence of a band shift to indicate the presence of an AR gene mutation in any of the three cases; in particular the two exons encoding the DNA binding domain of the AR were normal.

Table 2 Endocrine investigations and gonadal histology

\begin{tabular}{|c|c|c|c|}
\hline & Case 1 & Case 2 & Case 3 \\
\hline HCG simulation test & 500 units HCG single dose & 500 units HCG for 3 days & Not done \\
\hline Testosterone $(\mathrm{nmol} / \mathrm{l})$ & $\begin{array}{ll}\text { Pre } & \text { Post } \\
12 & 28\end{array}$ & $\begin{array}{ll}\text { Pre } & \text { Post } \\
7 \cdot 8 & 9 \cdot 4\end{array}$ & \\
\hline Dihydrotestosterone $(\mathrm{nmol} / \mathrm{l})$ & $2 \cdot 2 \quad 1.8$ & $0.4 \quad 0.53$ & \\
\hline Androstenedione ( $\mathrm{nmol} / \mathrm{l})$ & & $2 \cdot 8$ & \\
\hline $\begin{array}{l}\text { LH (U/1) } \\
\text { FSH (U/1) }\end{array}$ & $\begin{array}{l}7 \cdot 2 \\
2 \cdot 2\end{array}$ & & $<1$ \\
\hline Urinary steroid profile & Not done & Normal & Not done \\
\hline Histology & Normal testes & Normal testes & Not done \\
\hline
\end{tabular}


Table 3 Androgen binding in genital skin fibroblasts

\begin{tabular}{llll}
\hline & Case 1 & Case 2 & Case 3 \\
\hline $\begin{array}{l}\text { Bmax } \\
\text { (normal range } 1342.8 \pm 419 \times 10^{-18} \mathrm{~mol} / \mu \mathrm{g} \text { DNA) }\end{array}$ & 1136 & 949 & Not done* \\
$\begin{array}{l}\text { Kd } \\
\left.\text { (normal range } 1.08 \pm 0.252 \times 10^{-10} \mathrm{~mol} / \mathrm{l}\right)\end{array}$ & 0.71 & 1.0 & \\
\hline
\end{tabular}

Bmax, receptor concentration

$\mathrm{Kd}$, binding affinity.

$* 46, \mathrm{XY}$ sib with perineal hypospadias had normal androgen binding.

\section{Discussion}

Three cases of Down syndrome with a predominantly female phenotype are described with a $47, \mathrm{XY},+21$ karyotype, normal testosterone production and metabolism, and normal testicular histology in two of three cases. There was no evidence of a defect in steroid biosynthesis based on the adequate androgen response to HCG stimulation. Furthermore, gonadal dysgenesis possibly associated with a defect in a testis determining gene such as SRY, ${ }^{18}$ DAX-1, ${ }^{1920}$ or WT- $1,{ }^{21}$ is unlikely in view of the normal androgen response to HCG and normal testicular histology. Even though all three cases had features consistent with the diagnosis of AIS, no defect in the AR gene was detected by screening with PCR-SSCP analysis. This technique is a reliable screen based upon our previous work, ${ }^{17}$ and subsequently confirmed by direct sequence analysis (H R Davies, personal observation).

This cluster is possibly a chance occurrence. However, the finding of normal androgen binding and normal AR gene in one case with a typical CAIS phenotype and the other two cases at the extreme female end of the PAIS phenotypic spectrum is very uncommon, ${ }^{1314}$ and suggests that this cluster is more than mere coincidence. While it is interesting that a 46 , $\mathrm{XY}$ sib of case 3 who has complete sex reversal also has a severe genital anomaly, the cause in this instance is clearly unrelated to an extra chromosome 21. The finding of cases with chromosomal anomalies in association with disorders of sex differentiation provides potential evidence regarding the presence and action of genes postulated to regulate androgen activity. ${ }^{18}$ The presence of DS in these cases suggests that hitherto unrecognised genes on chromosome 21 may be involved in the pathway of sex differentiation. Chromosome 21 carries genes implicated in Alzheimer disease, familial amyotrophic lateral sclerosis, cystathioninuria, and acute megakaryocytic leukaemia. ${ }^{22}$ The common association of congenital heart disease and duodenal stenosis in DS has led researchers to postulate the existence of genes on chromosome 21 that are important in the development of the heart and the gastrointestinal system in both DS and normal subjects. ${ }^{23}$ No genes on chromosome 21 are at present known to be implicated in sex differentiation or androgen responsiveness. However, the common findings of minor undervirilisation in males with DS supports the hypothesis that genes on chromosome 21 may have a role in sex differentiation and androgen response. It is likely that features consistent with AIS may be under-reported in DS, as minor genital anomalies such as mild clitoromegaly or simple hypospadias are more likely to be disregarded in DS than in the general population.

One possible explanation is the presence of an SRY box (Sox) gene on chromosome 21, given the recent finding of an association between the Sox-9 gene and sex reversal in campomelic dysplasia. ${ }^{24}$ Sox genes are closely related to the SRY gene that determines testis development in mammals. SRY exerts its function through transcriptional control of unidentified genes "downstream" in the testis development pathway, and defects in SRY have been found to result in XY females with gonadal dysgenesis. ${ }^{1824}$ It is postulated that, like SRY, Sox genes may act as transcription factors in sex development control pathways, and some Sox genes have been identified as involved in sex differentiation. ${ }^{18}$ The phenotypic spectrum from a normal female phenotype and minor virilisation as described in these cases to the minor undervirilisation commonly reported in male DS may be explained by allelic heterogeneity in dosage sensitive Sox related genes on the trisomic chromosomes. ${ }^{1825}$ Further work is needed to characterise the defect in gonadal function in male DS patients and to determine whether chromosome 21 has a role in sex determination.

We are grateful to the following persons for providing clinical information relevant to the cases: Dr V Marrian, Consultant Paediatrician, Perth Royal Infirmary, Perth; Dr J A Sill, Consultant Paediatrician, St Helens and Knowlsley Hospital, Prescot, Merseyside; Dr P J Howard, Consultant Clinical Scientist, Merseyside and Cheshire Regional Cytogenetics Unit. Dr N Shimura was supported by a grant from Eli Lilly, Japan, and Shimura was supported by a grant from Eli Lilly, Japan, and
the work was funded by the Wellcome Trust. The help of the British Paediatric Association Surveillance Unit in identifying British Paediatric Association Surveillance Unit
cases for further study is gratefully appreciated.

1 Patterson MN, McPhaul MJ, Hughes IA. Androgen insensitivity syndrome. Hormones, enzymes and receptors. Clin Endocrinol Metab 1994;8:379-404.

2 Sheridan R, Llerena J, Matkins S, et al. Fertility in a male with trisomy 21 . F Med Genet 1989;26:294-8.

3 Smith GF, Berg JM. Down's anomaly. 2nd ed. Edinburgh: Churchill Livingstone, 1976:40-4.

4 Lang DJ, Dyke DCV, Heide F, et al. Hypospadias and urethral abnormalities in Down syndrome. Clin Pediat 1987;26:40-2.

5 Benda CE. The child with mongolism. New York: Grune and Stratton, 1960:124-9.

6 Peuschel SM, Orson JM, Boylan JM, et al. Adolescent development in males with Down syndrome. $A m \mathcal{F} D i$ Child 1985;139:236-8.

7 Hsiang YH, Berkovitz GD, Bland GL, et al. Gonadal function in patients with Down syndrome. Am F Med Genet 1987;27:449-58.

8 Santos-Mellos R, Souza OA, Santos-Mellos EMK, et al. Patient with Down's syndrome and pseudohermaphroditism with a $47 \mathrm{XY}+21 / 46 \mathrm{X}+21$ karyotype. hermaphroditism with a 47X

9 Golbus MS, Beauchamp CJ, Conte FA. Male pseudohermaphroditism in a child with Down's syndrome. $\mathcal{f} \mathrm{Med}$ Genet 1973;10:189-92.

10 Johannisson R, Gropp A, Winkling H, et al. Down's syndrome in the male: reproductive pathology and meiotic studies. Hum Genet 1983.63:132-8.

11 Jagiello G. Reproduction in Down's syndrome. In: Gerald PS, de la Cruz FF, eds. Trisomy 21 (Down syndrome) Baltimore: University Park Press, 1981

12 Horan RF, Beitins IZ, Bode HH. LHRH testing in men with Down's syndrome. Acta Endocrinol 1978;88:594-600.

13 Griffin JE. Androgen resistance - the clinical and molecular spectrum. N Engl f Med 1992;326:611-18.

14 McPhaul MJ, Marcelli M, Zoppi S, et al. The spectrum of mutations in the androgen receptor gene that causes androgen resistance. $\mathcal{F}$ Clin Endocrinol Metab 1993;76: $17-23$.

15 Evans BA, Hughes IA. Augmentation of androgen-receptor binding in vitro: studies in normals and patients with binding in vitro: studies in normals and patients with
androgen insensitivity. Clin Endocrinol 1985;23:567-77.

16 Evans BA, Jones TR, Hughes IA. Studies of the androgen receptor in dispersed fibroblasts: investigation of patients with androgen insensitivity. Clin Endocrinol 1984;20:93105 .

17 Batch JA, Williams DM, Davies HR, et al. Androgen receptor 
gene mutations identified by SSCP in fourteen subjects with androgen insensitivity syndrome. Hum Mol Genet 1992:1:497-503.

18 Goodfellow PN, Lovell-Badge R. SRY and sex determination in mammals. Annu Rev Genet 1993;3:71-92.

9 Zanaria E, Muscatelli F, Bardoni B, et al. An unusual member of the nuclear hormone receptor superfamily responsible for X-linked adrenal hypoplasia congenita. Nature 1994;372:635-41.

20 Bardoni B, Zanaria E, Guioli S, et al. A dosage sensitive locus at chromosome Xp21 is involved in male to female sex reversal. Nature Genet 1994;7:497-501.

21 Clarkson PA, Davies HR, Williams DM, et al. Mutational screening of the Wilms's tumour gene, WT1, in males screening of the Wilms's tumour gene, WT1, in males
with genital abnormalities. $₹$ Med Genet 1993;30:767-72.
22 Patterson D, Rahmani Z, Donaldson D, et al. Physical mapping of chromosome 21 . In: The phenotypic mapping
of Down syndrome and other aneuploid conditions. New York: of Down syndrome

23 Korenberg JR. Toward a molecular understanding of Down syndrome. In: The phenotypic mapping of Down syndrome and other aneuploid conditions. New York: Wiley-Liss, 1993.

24 Foster JW, Dominguez-Steglich MA, Guioli S, et al. Campomelic dysplasia and autosomal sex reversal caused by mutations in an SRY-related gene. Nature 1994;372:52530 .

25 Ogata T, Hawkins JR, Taylor A, et al. Sex reversal in a child with a $46, X, Y, X p+$ karyotype: support for the existence of a gene (s), located in distal Xp, involved in testis formof a gene(s), located in distal Xp, in. 